\title{
Changes in Intensity-Frequency-Duration Relationship of Heavy Rainfalls at a Station in Melbourne
}

\author{
$\underline{\text { A.G Yilmaz }^{a}}$ and B.J.C. Perera ${ }^{a}$ \\ ${ }^{a,}$ College of Engineering and Science, Victoria University, VIC 8001, Australia \\ Email:Abdullah.yilmaz@vu.edu.au
}

\begin{abstract}
A primary concern in the context of climate change impacts is related to the increase in the intensity and frequency of heavy rainfall events. The risk of heavy rainfall events (i.e. floods and drought) has increased over the world, and the intensity and frequency of heavy rainfall events are very likely to increase in the future with the exception of the regions with very significant decreases in rainfall.

More intense and frequent heavy rainfalls due to climate change and variability are a major concern for urban and rural flooding that causes damage to hydraulic structures such as dams, roads and stormwater drainage systems. Potential impacts of climate change on heavy rainfalls question the accuracy of current design rainfalls, which are used in estimating the hydraulic capacity of these structures. If there is a significant trend in heavy rainfall events, currently used design rainfalls obtained through Intensity-Frequency-Duration relationship may cause hydraulic failures and flood damages in case of underestimation. On the other hand, it would be a waste of money in the event of overestimation of design rainfalls.
\end{abstract}

In this study, first heavy rainfall trends for daily and sub-daily storm durations were investigated. Rainfall data from the Melbourne Regional Office station over the period of 1880-2010 were used for trend analysis of heavy rainfalls. The non-parametric rank based Mann-Kendal and Spearman's Rho tests were selected for trend analysis in this study due to distribution free characteristic of these tests. The Mann-Kendal and Spearman's Rho tests were applied to detect trends in annual maximum rainfall intensities of the selected storm durations (i.e. 6, 12, 18 and 30 minute, and 1, 2, 3, 6, 12, 24, 48 and 72 hour). The trend tests showed statistically significant increasing trends for sub-hourly storm durations (6, 12, 18 and 30 minute). Also, the data sets of 1, 2 and 3 hour storm durations indicated increasing trends, but not significant even at 0.1 significance level. On the other hand, $6,12,24,48$, and 72 hour heavy rainfall data sets showed statistically insignificant decreasing trends.

Then, the changing character of rainfall Intensity-Frequency-Duration (IFD) relationships were quantified through the analysis of four time slices (i.e. 1880-1909, 1910-1949, 1950-1979 and 1980-2010) using rainfall data from the Melbourne Regional Office station in Melbourne. The results of the frequency analysis of heavy rainfalls for 4 time slices showed that the IFD relationships vary over the period 1880-2010. Remarkable increases in sub-hourly design rainfall intensities were detected for the time slice 1980-2010. However, there is no evidence to state that increases in design rainfall intensities are statistically significant.

This study aims to demonstrate a methodology for the investigation of heavy rainfall trends and IFD relationship using rainfall data from a single station in Melbourne. Therefore, it is not realistic to extrapolate the findings of this study without further analysis using data of the many stations.

Keywords: Climate change, rainfall intensity-frequency-duration relationship, generalized extreme value, annual maximum series 


\section{INTRODUCTION}

A primary concern in the context of climate change impacts is related to the increase in the intensity and frequency of heavy rainfall events. The risk of heavy rainfall events (i.e. floods and drought) has increased over the world (Jung et al. 2011) and the intensity and frequency of heavy rainfall events are very likely to increase in the future with the exception of the regions with very significant decreases in rainfall (IPCC 2007).

One of the main questions about the heavy rainfall events is whether their occurrence is increasing or decreasing over time (Marengo et al. 2010). There are several studies investigating heavy rainfall trends over the different parts of the world. For example, Zhai et al. (2005) reported increasing trends in daily extreme rainfalls in western China, and also parts of southwest and southern China using the data covering the period of 1951-2000. Fujibe (2008) found significant upward trends in heavy daily rainfalls using the data over the period of 1901-2006 in Japan. Although many studies investigating rainfall trends in Australia (e.g. Murphy and Timbal 2008; Barua et al. 2012) were available in literature, studies with a focus on heavy rainfall trends in Australia are relatively limited. For example, Groisman et al. (2005) found an upward trend in number of days with heavy rainfalls (greater than 99.7 percentile) in south eastern Australia. Gallant et al. (2007) investigated rainfall trends including heavy rainfall events (95th and 99th percentiles) over two periods (i.e. 1910-2005 and 1951-2005) in southwest and east of Australia.

More intense and frequent heavy rainfalls due to climate modes and climate change are a major concern for urban and rural flooding that causes damage to hydraulic structures such as dams, roads and stormwater drainage systems. Potential impacts of climate change on heavy rainfalls question the accuracy of current design rainfalls used in estimation of the hydraulic capacity of these structures. If there is a significant trend in heavy rainfall events, currently used design rainfalls obtained through Intensity-Frequency-Duration curves may cause hydraulic failures and flood damages in case of underestimation. On the other hand, it would be a waste of money in the event of overestimation of design rainfalls.

This study aims to demonstrate a methodology for the investigation of heavy rainfall trends and IFD relationship using rainfall data from a single station (Melbourne Regional Office Station) in Melbourne. First, heavy rainfall trends for the storm durations including 6,12, 18 and 30 minute, and 1, 2, 3, 6, 12, 24, 48 and 72 hour were investigated. Then, the changing character of rainfall IFD relationships were quantified through the analysis of four time slices over the period 1880-2010.

\section{DATA}

Daily and 6 minutes data of the Melbourne Regional Office rainfall station were obtained from the National Climate Centre of the Bureau of Meteorology, Melbourne (BOM) and used for the purposes of this study. Corrected and quality controlled daily data were available since April 1855 and they were used to generate 48 and 72 hour rainfall durations data. The 6 minutes pluviometer data were available between April 1873 and December 2010, and they were used to produce 12, 18 and 30 minute, and 1, 2, 3, 6 and 12 hour rainfall data. There were no missing data in daily rainfall record, but there was a missing data period from January 1874 to July 1877 in six minute data record. Thus, the data over the period of 1880-2010 were used in this study. It should be noted that there was also another major missing data period from July 1914 to December 1924 during World War I and this period was not considered in this study.

\section{METHODOLOGY}

\subsection{Trend Tests}

The non-parametric rank based Mann-Kendal (MK) and Spearman's Rho (SR) tests were used to detect trends in annual maximum rainfall intensities of the selected storm durations (i.e. 6, 12, 18 and 30 minute, and 1, 2, 3, 6, 12, 24, 48 and 72 hour) in this study. Details of the tests can be found in Yue et al. (2002).

\subsection{Frequency Analysis of Annual Maximum Rainfalls}

Rainfall data from January 1880 to December 2010 were considered in this study. The entire rainfall data series was split into 4 time slices. Each time slice includes approximately 30 years data. Followings are the time slices used in this study: 
Time slice 1: 1880-1909: 29 Years

Time slice 2: 1910-1949: 28 Years (1914-1924 is a missing data period)

Time slice 3: 1950-1979: 30 Years

Time slice 4: 1980-2010: 31 Years.

There are two main approaches to extract the heavy rainfall data from the rainfall records for frequency analysis: (1) selecting the maximum rainfall events for each year and producing annual maximum series (AMS) and (2) selecting the rainfall events over a certain threshold and producing peaks over threshold (POT) series (Begueria 2005). In this study, the AMS method was used to generate heavy rainfall data series to be used in Generalized Extreme Value (GEV) distribution as recommended by several studies (e.g. Sugahara et al., 2009; Park et al., 2011). Heavy rainfall frequency analysis was done for four different time slices. Details of the GEV distribution can be seen in Park et al. (2011). The L-moments method was selected for estimation of GEV parameters in this study due to relatively unbiased characteristic of L-moments for small samples (Borijeni and Sulaiman, 2009). The details of the L-moments method can be found in Yurekli et al. (2009).

\section{RESULTS}

The MK and SR tests showed significant increasing trends in heavy rainfalls (i.e. annual maximums) for short storm durations including 6,12,18 and 30 minute. Also, the data sets of 1,2 and 3 hour indicated increasing trends, however they are not significant even at 0.1 significance level. On the other hand, 6,12 , 24,48 , and 72 hour heavy rainfall data sets showed statistically insignificant decreasing trends. Table 1 demonstrates the results of the trend tests.

Table 1. Trend test results

\begin{tabular}{|c|c|c|c|}
\hline $\begin{array}{c}\text { Storm } \\
\text { Durations }\end{array}$ & $\begin{array}{c}\text { Mann-Kendal } \\
\text { Test } \\
\end{array}$ & $\begin{array}{c}\text { Spearman's Rho } \\
\text { Test }\end{array}$ & Result \\
\hline \multicolumn{4}{|c|}{ Test Statistics } \\
\hline $6 \mathrm{~min}$ & 2.117 & 2.147 & $\mathrm{~S}(0.05)$ \\
\hline $12 \mathrm{~min}$ & 2.684 & 2.574 & $\mathrm{~S}(0.01)[\mathrm{MK}], \mathrm{S}(0.05)[\mathrm{SR}]$ \\
\hline $18 \mathrm{~min}$ & 2.117 & 2.158 & $\mathrm{~S}(0.05)$ \\
\hline $30 \mathrm{~min}$ & 1.779 & 1.783 & $\mathrm{~S}(0.1)$ \\
\hline $1 \mathrm{hr}$ & 0.895 & 0.883 & NS \\
\hline $2 \mathrm{hr}$ & 0.656 & 0.673 & NS \\
\hline $3 \mathrm{hr}$ & 0.53 & 0.6 & NS \\
\hline $6 \mathrm{hr}$ & -0.335 & -0.362 & NS \\
\hline $12 \mathrm{hr}$ & -1.316 & -1.266 & NS \\
\hline $24 \mathrm{hr}$ & -0.381 & -0.372 & NS \\
\hline $48 \mathrm{hr}$ & -0.491 & -0.465 & NS \\
\hline $72 \mathrm{hr}$ & -1.047 & -0.995 & NS \\
\hline
\end{tabular}

Critical Values at $0.1,0.05$, and 0.01 significance levels are $1.645,1.96$, and 2.576 respectively. $\mathrm{S}=$ statistically significant trends at different significance levels shown within brackets. $\mathrm{NS}=$ statistically insignificant trends even at 0.1 significance level.

Figure 1 shows the heavy rainfall intensity time series plots for the storm durations showing statistically significant increasing trends. 


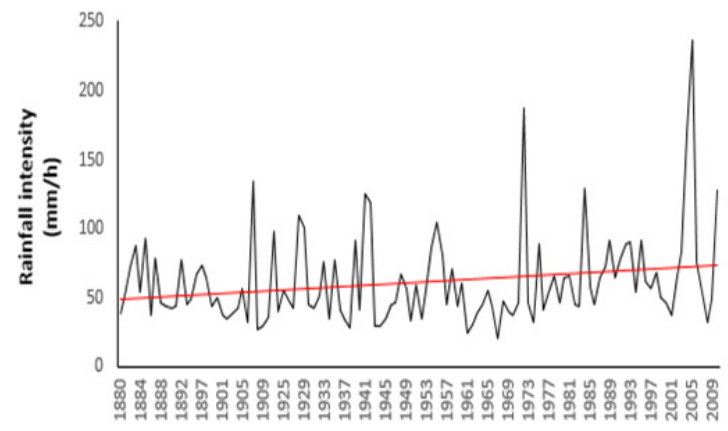

a) $6 \mathrm{~min}$

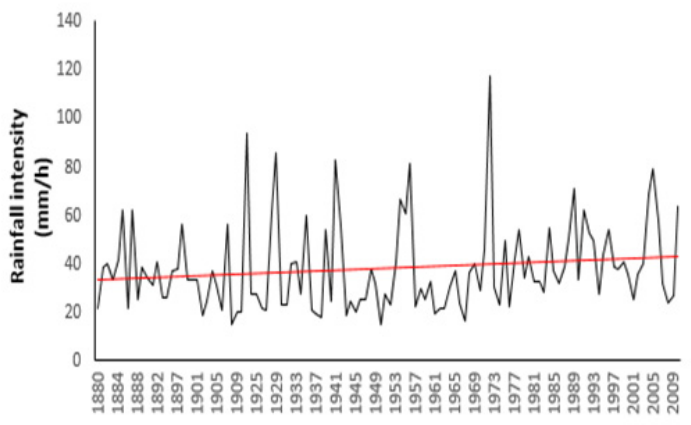

c) $18 \mathrm{~min}$

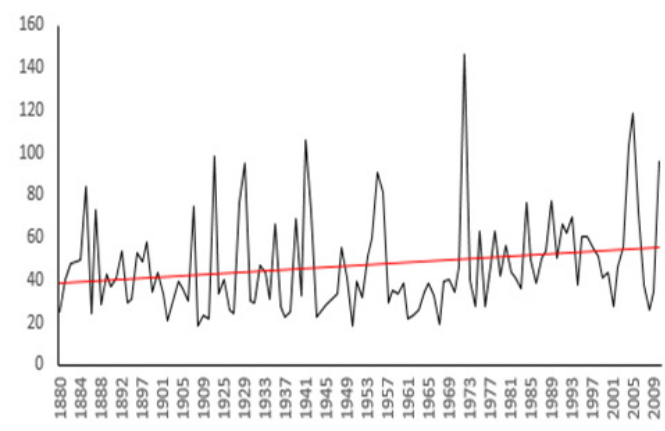

b) $12 \mathrm{~min}$

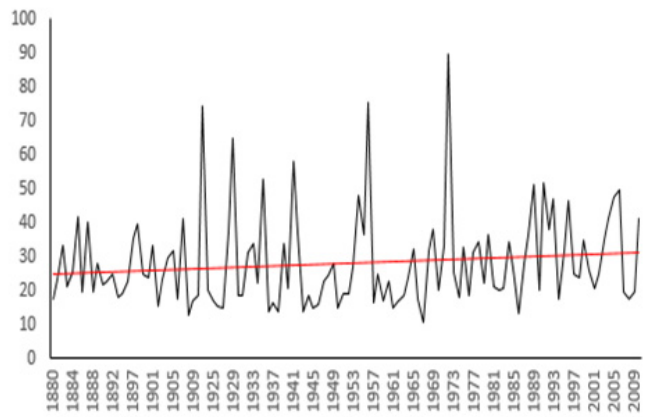

d) $30 \mathrm{~min}$

Figure 1. Heavy rainfall intensity time series plots for storm durations showing statistically significant increasing trends

The results of the frequency analysis of heavy rainfalls for the 4 time slices showed that the IFD curves vary over the period 1880-2010. Figure 2 demonstrates the rainfall intensity of storms of different durations over the 4 time slices with respect to their return periods. The most noticeable changes were observed between time slices 1 and 4 . Substantial increases were detected between slices 1 and 4 for sub-hourly storm durations in particular for short return periods. However, increases were not consistent in between time slices 1 and 4 (i.e. upward and downward trends but not a consistency). Time slice 3 showed the higher rainfall intensities for hourly and daily storm durations for all return periods except 2 years, whereas the time slice 4 demonstrated the higher rainfall intensities of all sub-hourly storm durations for the return periods up to 10 years.

The $90 \%$ confidence intervals of GEV models for the 4 slices were generated. It was found that upper and lower confidence limits of the time slice 4 are higher than the other time slices for sub-hourly storm durations of the return periods especially less than 20 year. On the other hand, confidence limits of the time slice 3 showed higher values than the other time slices for hourly and daily storm durations of all return periods. Despite above explained differences in confidence limits, for almost all storm durations and return periods, rainfall distributions of 4 time slices have overlapping confidence limits based on the comparison of the upper and lower confidence limits. Therefore, there is not sufficient evidence to state that differences in rainfall intensity estimates are statistically significant. 

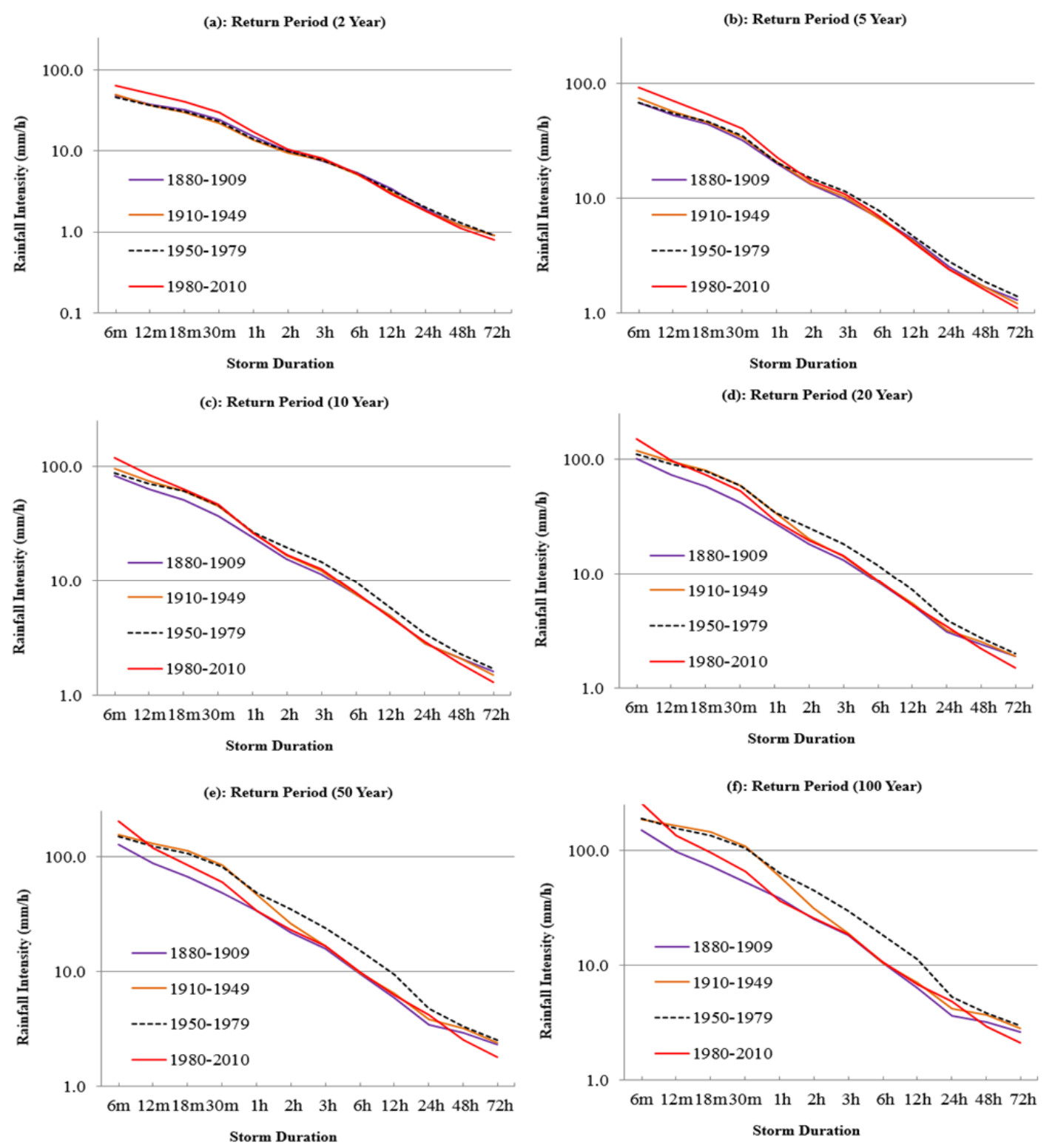

Figure 2. Rainfall intensity estimates for 4 time slices

The heavy rainfall frequency analysis showed some evidence of the changing character of short duration storms over 1880-2010 based on an analysis of the rainfall data from Melbourne Regional Station, although they are not statistically significant. Climate change and natural climate variability can be shown as reasons behind the differences in IFD information. Anthropogenic climate change can affect the rainfalls directly, as well as the dynamics of key climate modes. Murphy and Timbal (2008) and CSIRO (2010) stated that despite the lack of evidence of the direct relationship between rainfall change and the anthropogenic climate change, change in rainfalls is associated at least partially to the climate change in south eastern Australia. Nevertheless, it is quite difficult to address anthropogenic climate change effects on the heavy rainfalls and climate modes due to the limited historical record and strong effects of natural climate variability (Westra et al. 2010). Some of the climate modes, which are effective on Australian rainfall variability, are the El NinoSouthern Oscillation (Verdon et al. 2004, Mekanik and Imteaz 2012a), the Indian Ocean Dipole (Ashok et al. 2003, Mekanik and Imteaz 2012b,c ), the Southern Annual Mode (Meneghini et al. 2007) and Inter-decadal Pacific Oscillation (Verdon-Kidd and Kiem 2009). Further analysis needs to be conducted to investigate the reasons for recent rainfall trends and patterns for the study area, but this is beyond the scope of this paper. 
Using only one station's rainfall data is an important limitation of this study. It should be noted that it is not realistic to extrapolate the findings of this paper for larger spatial scales without further analysis using rainfall data of many stations.

\section{CONCLUSIONS}

This study investigated the heavy rainfall (i.e. annual maximum) trends and changes in Intensity-FrequencyDuration (IFD) information over time for a rainfall station in Melbourne. It has been found that sub-hourly storm durations showed statistically significant increasing trends. There are also upwards (i.e. 1, 2 and 3 hour) and downward (i.e. 6, 12, 24, 48 and 72 hour) trends for other storm durations but not statistically significant. Moreover, noticeable differences was found in the sub hourly rainfall intensities for all return periods between first and last time slices. However, changes in rainfall intensities between the other time slices were not consistent.

This study shows some evidence of the changing character of heavy rainfalls for short storm durations. It is recommended to conduct studies using a similar methodology with data from many stations to have more accurate conclusions. It is also recommended to investigate the future rainfall IFD relationships through the analysis of future rainfall data derived from global and regional climate models under different greenhouse gas emission scenarios since the intensity and frequency of heavy rainfall events are very likely to increase in the future.

\section{REFERENCES}

Ashok, K., Guan, Z., and Yamagata,T. (2003). Influence of the Indian Ocean Dipole on the Australian winter rainfall. Geophysical Research Letters, 30, doi: 10.1029/2003GL017926.

Barua, S., Muttil, N., Ng, A.W.M., and Perera, B.J.C. (2012). Rainfall trend and its implications for water resource management within the Yarra River catchment, Australia. Hydrological Processes, 27 (12), 17271738.

Beguería, S. (2005). Uncertainties in partial duration series modelling of extremes related to the choice of the threshold value. Journal of Hydrology, 303 (1-4), 215-230.

Borujeni, S.C. and Sulaiman, W.N.A. (2009). Development of L-moment based models for extreme flood events. Mathematical Journal of Mathematical Sciences, 3 (2), 281-296.

CSIRO, (2010) 'Climate variability and change in south-eastern Australia: A synthesis of findings from Phase 1 of the South Eastern Australian Climate Initiative (SEACI)', viewed on September 05, 2012, http://www.seaci.org/publications/documents/SEACI-1\%20Reports/Phase1_SynthesisReport.pdf.

Fujibe, F. (2008). Long-Term Changes in Precipitation in Japan. Journal of Disaster Research, 3(1), 51-52.

Gallant, A.J.E., Hennessy, K.J. and Risbey, J. (2007). Trends in rainfall indices for six Australian regions: 1910-2005. Australian Meteorological Magazine, 56, 223-239.

Groisman, P. Y., Knight, R.W., Easterling, D.R., Karl, T.R., Hegerl, G.C., and Razuvaev, V.N. (2005). Trends in intense precipitation in the climate record. Journal of Climate, 615 (18), 1326-1350.

IPCC (2007) 'IPCC Fourth Assessment Report: Climate Change 2007', Working Group I: The Physical Science Basis, Precipitation Extremes and Droughts, Chapter 10, Intergovernmental Panel on Climate Change (IPCC), Viewed on July 04, 2012, http://www.ipcc.ch/publications_and_data/ar4/wg1/en/ch10s10es-4-precipitation-extremes.html

Jung, I-W., Bae, D-H, and Kim, G. (2011). Recent trends of mean and extreme precipitation in Korea. International Journal of Climatology, 31, 359-370.

Marengo, J.A., Rusticucci, M., Penalba, O. and Renom, M. (2010). An intercomparison of observed and simulated extreme rainfall and temperature events during the last half of the twentieth century: part 2: historical trends. Climatic Change, 98, 509-529.

Mekanik, F. and Imteaz, M.A. (2012a). Forecasting Victorian spring rainfall using ENSO and IOD: A comparison of linear multiple regression and nonlinear ANN, 2nd International Conference on Uncertainty Reasoning and Knowledge Engineering, Jakarta, August. 
Mekanik, F. and Imteaz, M.A. (2012b). A Multivariate Artificial Neural Network Approach for Rainfall Forecasting: Case Study of Victoria, Australia, World Congress on Engineering and Computer Science 2012, San Francisco, October.

Mekanik, F. and Imteaz, M.A. (2012c). Artificial Neural Networks (ANN) modelling of spring rainfall using dual-climate indices for Victoria, Hydrology and Water Resources Symposium, Sydney, November.

Meneghini, B., Simmonds, I. and Smith, I.N. (2007). Association between Australian rainfall and the Southern Annular Mode. International Journal of Climatology, 27, 109-121.

Murphy, B.F., and Timbal, B. (2008). A review of recent climate variability and climate change in southeastern Australia. International Journal of Climatology, 28, 859-879.

Park, J-S., Kang, H-S., Lee, Y.S., and Kim, M-K. (2011). Changes in the extreme daily rainfall in South Korea. International. Journal of Climatology, 31, 2290-2299.

Sugahara, S., da Rocha, R.P., and Silveira, R. (2009). Non-stationary frequency analysis of extreme daily rainfall in Sao Paulo, Brazil. International Journal of Climatology, 29, 1339-1349.

Verdon-Kidd, D.C., and Kiem, A.S. (2009). On the relationship between large-scale climate modes and regional synoptic patterns that drive Victorian rainfall. Hydrology Earth System Sciences, 13, 467-479.

Verdon, D.C., Wyatt, A.M., Kiem, A.S., and Franks, S.W. (2004). Multi-decadal variability of rainfall and streamflow- Eastern Australia. Water Resources Research, 40, W10201,doi:10210.11029/12004WR003234.

Westra, S., Varley, I., Jordan, P., Nathan, R., Ladson, A., Sharma, A., and Hill, P. (2010). Addressing climate non-stationarity in the assessment of flood risk. Australian Journal of Water Resources, 14 (1), 1-16.

Yue,S. Pilon, P., and Cavadias, G. (2002). Power of the Mann Kendall and Spearman's rho tests for detecting monotonic trends in hydrological series. Journal of Hydrology, 259 (1-4), 254-271.

Yurekli, K, Modarres, R. and Ozturk, F. (2009). Regional daily maximum rainfall estimation for Cekerek Watershed by L-moments. Meteorological Applications, 16, 435-444.

Zhai, P., Zhang, X., Wan, H., and Pan, X. (2005). Trends in Total Precipitation and Frequency of Daily Precipitation Extremes over China. Journal of Climate, 18, 1096-1108. 